\title{
A MODEL FOR ASSESSING THE DIGITAL TRANSFORMATION READINESS FOR VIETNAMESE SMES
}

\author{
Nguyen Thi Xuan Hoa \\ Industrial Management Department, School of Economics and Management, Ha Noi \\ University of Science and Technology, Vietnam \\ Nguyen Thanh Tuyen \\ Industrial Management Department, School of Economics and Management, Ha Noi \\ University of Science and Technology, Vietnam
}

\begin{abstract}
The paper aims to develop an econometric model for the routine diagnosis of enterprises' level of readiness for digital transformation (DT) on the example of small and medium-sized enterprises (SMEs) in Vietnam. The use of questionnaires allowed obtaining quantitative estimates of SMEs' level of readiness for DT in Vietnam. Factor analysis with the principal component method determines the list of factors of SMEs' readiness for DT. The ranges of the level of preparedness in Vietnam were determined, resulting in the classification of enterprises in the groups of "Newcomers," "Learners," and "Leaders" according to their use of digital technology and smart manufacturing. The integral index made it possible to quantify the impact of DT's readiness on SMEs' sustainability. The study results revealed that the nature of the impact depends on the level of SMEs' readiness for DT.
\end{abstract}

Keywords: digital transformation, small and medium-sized enterprises, Vietnam, business readiness, digital technologies, sustainable development

DOI: http://dx.doi.org/10.15549/jeecar.v8i4.848

\section{INTRODUCTION}

Global modern social and economic development is characterized by a radically new approach to production based on: scaling automation of business processes, the widespread introduction of information technology, and artificial intelligence in industry. According to estimates of the World Economic Forum, by 2025, more than half of the world economy will already operate based on digital technologies, which will allow businesses to earn more than 30 trillion dollars extra (World Economic Forum, 2021). Capgemini Consulting and the Sloan School of Management have found that companies will become less competitive in the marketplace by avoiding and disregarding the digitalization of economic processes, and profit levels will decrease by up to 24 percent per year (Massachusetts Institute of Technology, 2021). At the same time, more than $40 \%$ of the leading companies in their industry may be displaced from the market in the next five years if they lack the DT business model (Berman \& Papas, 2021).

Global trends of active detailing of economic processes have necessitated the digitalization of production in Vietnam, where the business efficiency and competitiveness of the national economy are to be improved. Today, most companies, industries, and business structures in Vietnam are just beginning the digitalization 
process; at the beginning of 2021, the country's digital economy amounted to $8.2 \%$ of GDP. At the end of 2020, the country had one of the lowest levels of e-commerce in Southeast Asia (within 3\% of the country's retail turnover). Yet, it should be noted that during the 2016-2020 period, foreign investors invested about $\$ 1.9$ billion in the digitalization of Vietnam's economy, which served to accelerate the pace of digital development in the country (Quynh, 2021). Vietnam approved the National DT Program up to 2025 with a focus on 2030 that implies Vietnam's among the top 50 countries in the UN's ICT Development Index and GDP growth of 30\% by 2030 (Ministry of Information and Communications, 2020). Despite some losses to the Vietnamese economy due to the COVID-19 pandemic, social media account activity increased by 7 million between 2020 and 2021, reaching a penetration rate of $73.3 \%$
(Ministry of Planning and Investment, 2021). Due to Vietnam's current high level of internet access and high school students' academic performance, the progressive development and production of $5 \mathrm{G}$ equipment have a vast potential to blossom in the country's digitalization. According to the report, "By 2045, changes in awareness, corporate strategies, and incentives to digitalize business, administration and production activities may allow DT to provide an increase in GDP to $\$ 60.9$ billion with a steady $0.38 \%$ annual growth rate, while the information economy will increase to $\$ 168.9$ billion in the next 27 years (Table 1 ) (Cameron et al., 2019). However, these figures can only be achieved with the active participation of the SME sector in DT, which accounts for more than $97 \%$ of all enterprises and accounts for about 50\% of Vietnam's GDP (Ministry of Planning and Investment, 2021).

Table 1: Scenarios for Vietnam's digital economy in 2045

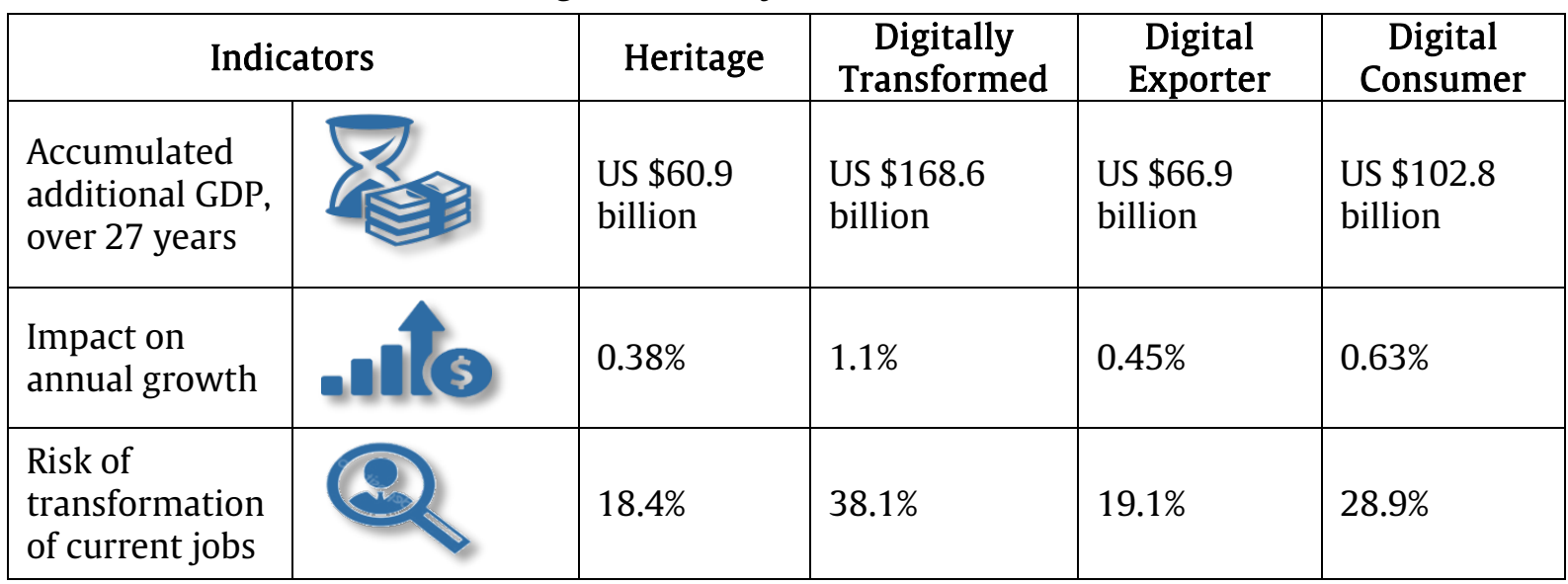

It should be noted that big businesses in Vietnam provide the accelerated development of the DT economy. At the same time, the SME sector has faced a certain kind of pressure, as they cannot ensure rapid innovation in the production process, management system, or compete with large companies. Even though almost all the country's SMEs are aware of the DT need and benefits, about $60 \%$ of SMEs in Vietnam do not have enough resources to implement digital technology in the business process (PwC, 2021).

According to Rosenberg (2020), the digital maturity of small and medium-sized enterprises (SMEs) is only at the level of understanding and initial implementation. Because DT is a long-term process, the positive synergetic effect depends on each individual business unit, so it is relevant to seek the most effective approaches to adaptation of SMEs to digitalization. This, in turn, requires the development of a comprehensive assessment system based on a variety of correlated indicators of the economic status and digitalization potential of economic activities of companies, as well as the readiness for DT. In this paper, we developed a model to systematically evaluate companies' state-ofreadiness in relation to the DT vision and assessment of its efficiency to ensure sustainable business development on the example of SMEs in Vietnam.

\section{LITERATURE REVIEW}

Numerous methods for assessing DT readiness were presented in the scientific 
literature (Mittal et al., 2018; Nick et al., 2019; Castelo-Branco et al., 2019; Hitz \& Schwer, 2018; Schwer \& Hitz, 2018). In his scientific work, Mittal et al. (2018) explored the problems and attendant factors of the maturity of companies and businesses in general to DT. Scientists have developed an empirical scale of qualitative and quantitative parameters for assessing an organization's readiness to implement digital technologies. A comprehensive system of criteria for evaluating readiness has been developed, for example, customer, operation, culture, innovation, performance, and resources (Jung et al., 2016; Schuh et al., 2020; BrunetThornton et al., 2019). Maturity parameters for organizations are highly differentiated. The SIRI's assessment questionnaire and I Bench's maturity model contain 16 items. Another includes 139 questions (Axmann \& Harmoko, 2020). An exciting methodology for assessing the readiness of an organization for IT implementation VDMA. It was based on 18 points of complexity parameters, characterized by quality levels of enthusiasm and professionalism in the DT implementation process: from the readiness level of an outsider to an expert and the best performer (Lichtblau et al., 2015). This approach is beneficial for the organization's self-assessment to understand the current state of readiness for DT.

Through studying smart manufacturing models in the world, such as Singapore's SIRI model, Taiwan's iBench model, VDMA's IMPULS model, Deloitte model, Openroad model, and Acatech model, providing a solid foundation for assessing the readiness of companies in DT (Jung et al., 2016; Schuh et al., 2020; Axmann \& Harmoko, 2020; Lichtblau et al., 2015; Singapore Economic Development Board, 2019).

By applying those models, which are suitable for standardized and well-founded enterprises, many important steps in the process of successfully using DT are taken. However, Vietnamese enterprises, especially SMEs, still have a large gap to apply the complete model as above. Vietnamese SME enterprises have many unique factors. The awareness of business leaders about the necessity of DT, smart production, application of basic management tools in production such as Manufacturing JIT, Lean, Total productivity management still have many limitations, and the machinery systems are still not synchronized. Therefore, it is necessary to have a suitable DT readiness assessment model to evaluate limitations and build an appropriate DT roadmap for Vietnamese SMEs.

\section{RESEARCH METHODOLOGY}

\section{Evaluating the Readiness of Vietnamese SMEs DT}

In this study, we focus on building a DT readiness assessment model suitable to the characteristics of Vietnamese SMEs through 4 main dimensions of aspects with 16 variables that correspond to the areas of digital technologies use (Table 2).

Table 2: Model for evaluating the readiness of Vietnamese SMEs DT

\begin{tabular}{|l|l|}
\hline \multicolumn{1}{|c|}{ Dimensions } & \multicolumn{1}{|c|}{ Variables } \\
\hline \multirow{5}{*}{ Enterprise Management } & Leadership \\
\cline { 2 - 2 } & Customer \\
\cline { 2 - 2 } & Human Resources \\
\cline { 2 - 2 } & Innovation culture \\
\hline \multirow{5}{*}{ Productivity Management } & Standards, management tools \\
\cline { 2 - 2 } & Level of application \\
\cline { 2 - 2 } & Process control \\
\cline { 2 - 2 } & Performance measurement \\
\hline \multirow{5}{*}{ Smart Manufacturing } & Infrastructure platform \\
\cline { 2 - 2 } & Strategy for DT \\
\cline { 2 - 2 } & IT applications for DT \\
\cline { 2 - 2 } & Innovation management \\
\cline { 2 - 2 } & Using sensor system in-process monitoring \\
\cline { 2 - 2 } & Building IT solutions \\
\cline { 2 - 2 } & Building a cloud-based database \\
\cline { 2 - 2 } & Application of Industry 4.0 solutions \\
\hline
\end{tabular}


Variables of models for assessing the readiness of Vietnamese SMEs DT are generated based on (Axmann \& Harmoko, 2020; Singapore Economic Development Board, 2019; Jung et al., 2016; Schuh et al., 2020). Then consulted with experts and selected 16 observed variables. The expert group of 40 people included equipment suppliers, system builders for smart production, and scholars at the country's leading universities: Hanoi University of Science and Technology, Le Quy Don University of Science and Technology, Viet Nam National University Ho Chi Minh City.

The difference between this model and previous models is that it includes enterprise management and product management dimensions in the assessment model. Since these are dimensions that many Vietnamese SMEs are still limited to and need to be assessed to measure the ability to convert to intelligent manufacturing sustainably and systematically (Axmann \& Harmoko, 2020; Jung et al., 2016).

To assess the readiness of Vietnamese SMEs DT, a survey was carried out within ten months in 2020. Total 510 companies participated in the survey, in which enterprises work in a field of manufacturing and processing industry accounts for the majority (33\% of the sampling frame). In addition, there is participation from many enterprises in many other fields such as wholesale, retail, auto garage $(8 \%$ of the sampling frame); construction (6\%); food and lodging (6\%); agriculture, forest and aquaculture (6\%); professional, scientific, and technical services (5\%); information and communication services (4\%); education and training services (4\%); financial, banking and insurance services $(1 \%)$; logistics $(1 \%)$; water supply, waste disposal and wastewater treatment and management (1\%), other services (25\%). Middle and top managers of the corresponding SME enterprises participated in the survey (10-13 representatives from an enterprise). The questionnaire consisted of 16 questions, each aimed at assessing the degree of development at the enterprise of the relevant sphere of digital technology use, given in Table 1. The questionnaire can be found at the link (Google Forms, 2021). The questionnaire adopted 5 points Likert scale comprising a range of strongly agree (5 points) to disagree (1 point) strongly.
The research used SPSS 23.0 software to assist in analyzing the data set after collection and used Cronbach's alpha test method to measure the reliability of the scales. Then all observed variables were calculated factor loading to ensure that all observed variables had high reliability and were considered to be of practical significance. A Bartlett's test was run to calculate the Kaiser-Meyer-Olkin criterion (KMO) and Significance coefficient (Sig.) to determine if there are statistically significant correlations between observed variables. This is a condition for confirmation the observations are suitable for factor analysis. Exploratory Factor Analysis (EFA) with the principal component method is performed to group observed variables into factors on the principle of ensuring monism and convergence. Confirmatory factor analysis (CFA) evaluates the fit of the Model Fit according to the indicators and conditions studied (Menke, 2018).

The results of the assessment of the readiness of Vietnamese SMEs DT can be seen as representative because:

- The sample is sufficient (510 enterprises with $p=0.05$ significance level for the population (Taherdoost, 2017);

- Representatives of enterprises of different categories participated in the survey: FDI enterprises, Non-state enterprises, and State-owned enterprises;

- The opinions of management representatives for each company were consistent (coefficient of variation $(\leq$ 9.76\%) not exceeding 10\% (Khaw et al., 2018));

\section{Evaluating the Performance of Vietnamese SMEs DT for Sustainable Business Development}

To assess the impact of the readiness of Vietnamese SMEs DT, we used linear and nonlinear regression analysis methods in the EViews 10 software. The sustainable business development indicator was used as a dependent variable $\left(I_{S D}\right)$, the readiness of Vietnamese SMEs DT indicator was used as an in dependent variable $\left(R_{D T}\right)$. The independent variable was calculated based on the questionnaire points as arithmetic mean score for all the questions in the questionnaire for the 
respondents (representatives of one enterprise). The calculation of the arithmetic mean value for the respondents within one enterprise is possible due to the low variability $(\leq 9.76 \%)$ of the assessments of the respondents (representatives of the same enterprise). To identify the features of the influence of the level of the readiness of SMEs DT on the sustainability of business development, the levels of the first indicator were determined. The range of actual values of the RDT indicator using the Student's test is divided into three levels: high, medium, and low. Indicator values that were not included in these ranges were used to assess intermediate levels.

The dependent variable of the model for assessing the impact of the readiness of Vietnamese SMEs DT on the sustainability of business development is represented by the integral indicator of sustainable development calculated for 2020 :

- return on assets;

- return on equity;

- growth rates of labor productivity compared to 2019;

- cost coverage;

- the growth rate of the average wage per employee compared to 2019;

- the rate of growth of the wage fund of the enterprise in comparison with 2019;

- $\quad$ staff retirement rate;

- the share of payments made by the company related to the emission of pollutants into the atmosphere in the company's revenue.

The list of particular indicators of business sustainability is determined based on (Chen et al., 2021; Khan et al., 2021). The cumulative percentage of the variance of the factors formed by the indicated indicators was $88.3 \%$.

Algorithm for calculating the integral indicator for assessing sustainable business development:

1. determining the sustainable development factors and their composition based on factor loadings of indicators based on the results of factor analysis;

2. determining the levels of particular indicators of sustainable development. Low, medium, high, as well as intermediate levels of sustainable development indicators are determined using the Student criterion similar to the levels of the indicator $R_{D T}$;
3. calculating sub-indicators of sustainable development by factors and integral indicator of sustainable development (ISD), determination of the range of their levels using the fuzzy set method (Galiakhmetova et al., 2019). The levels of these indicators are determined by dividing the range of possible values into five equal intervals (levels): low, medium, high, and intermediate.

The integral indicator of sustainable business development was calculated using the following formulas:

$$
\left.\begin{array}{c}
I_{S D}=\sum\left(w_{L} \times p_{i}^{L}+w_{M} \times p_{i}^{M}\right. \\
\left.+w_{H} \times p_{i}^{H}\right)
\end{array}\right) \begin{gathered}
1, S D_{i} \leq S D_{i 1} \\
p_{i}^{L}=\left\{\begin{array}{c}
\frac{S D_{i 2}-S D_{i}}{S D_{i 2}-S D_{i 1}}, S D_{i 1}<S D_{i}<S D_{i 2} \\
0, S D_{i} \geq S D_{i 2}
\end{array}\right. \\
p_{i}^{M}=\left\{\begin{array}{c}
0, S D_{i} \leq S D_{i 1}, S D_{i} \geq S D_{i 4} \\
\frac{S D_{i}-S D_{i 1}}{S D_{i 2}-S D_{i 1}}, S D_{i 1}<S D_{i}<S D_{i 2} \\
\frac{S D_{i 4}-S D_{i}}{S D_{i 4}-S D_{i 3}}, S D_{i 3}<S D_{i}<S D_{i 4} \\
1, S D_{i 2} \leq S D_{i} \leq S D_{i 3} \\
1, S D_{i} \geq S D_{i 4}
\end{array}\right. \\
p_{i}^{H}=\left\{\begin{array}{c}
S D_{i}-S D_{i 3} \\
\frac{S D_{i 4}-S D_{i 3}}{0} S D_{i 3}<S D_{i}<S D_{i 4} \\
0, S D_{i} \leq S D_{i 3}
\end{array}\right.
\end{gathered}
$$

with $W_{L}, W_{M}, W_{H}$ as correcting coefficients, which take values of 0.1 for a low level of stimulating indicators and a high level of stimulating indicators; 0.5 for the average level of indicators; 0.9 for a high level of stimulating indicators and a low level of nonstimulating indicators (Galiakhmetova et al., 2019);

$p_{i}^{L}, p_{i}^{M}, p_{i}^{H}$ as the probabilities of attributing $i$ indicator of sustainable development to low, medium, and high levels, respectively;

$S D_{i}$ as the value of $i$ indicator of sustainable development;

$S D_{i 1}, S D_{i 2}, S D_{i 3}, S D_{i 4}$ as the liminal values of $i$ indicator, which lay the basis for the classification by levels;

$S D_{i} \leq S D_{i 1}$ as the zone of $100 \%$ certainty of attributing $i$ indicator of sustainable development to the low level;

$S D_{i 2} \leq S D_{I} \leq S D_{i 3}$ as the zone of $100 \%$ certainty of attributing $i$ indicator of sustainable development to the medium level; 
$S D_{i} \geq S D_{i 4}$ as the zone of $100 \%$ certainty of attributing $i$ indicator of sustainable development to the high level;

\section{RESULTS}

Measure the Reliability of the Scales (Cronbach's Alpha) of the Questionnaire for the Readiness of Vietnamese SMEs DT
Through the results of Cronbach's alpha (Table 3), four groups of indicators of the readiness of Vietnamese SMEs DT have Cronbach's alpha coefficient from 0.853 to 0.908 are all greater than 0.6 . The variable-total correlation coefficient is from 0.617 to 0.826 , proving that all four groups of variables are satisfactory for the following exploratory factor analysis to reduce observed variables belonging to the research model.

Table 3: Measure the reliability of the scales using Cronbach's alpha test

\begin{tabular}{|l|l|l|l|l|l|}
\hline \multicolumn{1}{|c|}{$\begin{array}{c}\text { Labels of observed } \\
\text { variable }\end{array}$} & $\begin{array}{c}\text { Observed } \\
\text { variable }\end{array}$ & $\begin{array}{c}\text { Scale } \\
\text { Mean if } \\
\text { Item } \\
\text { Deleted }\end{array}$ & $\begin{array}{c}\text { Scale } \\
\text { Variance } \\
\text { if Item } \\
\text { Deleted }\end{array}$ & $\begin{array}{c}\text { Corrected } \\
\text { Item-Total } \\
\text { Correlation }\end{array}$ & $\begin{array}{c}\text { Cronbach's } \\
\text { Alpha if } \\
\text { Item } \\
\text { Deleted }\end{array}$ \\
\hline Enterprise Management & Cronbach's alpha $=0,908$ \\
\hline Leadership & QLDN1 & 7.72 & 11.793 & .817 & .873 \\
\hline Customer & QLDN2 & 7.78 & 11.907 & .774 & .887 \\
\hline Human Resources & QLDN3 & 7.82 & 10.964 & .826 & .869 \\
\hline Innovation culture & QLDN4 & 8.00 & 11.769 & .755 & .894 \\
\hline Productivity Management & Cronbach's alpha $=0,863$ & \\
\hline $\begin{array}{l}\text { Standards, management } \\
\text { tools }\end{array}$ & QLNS1 & 6.56 & 11.504 & .768 \\
\hline Level of application & QLNS2 & 6.61 & 11.468 & .758 & .806 \\
\hline Process control & QLNS3 & 6.49 & 11.988 & .705 & .828 \\
\hline Performance measurement & QLNS4 & 6.99 & 12.973 & .617 & .862 \\
\hline $\begin{array}{l}\text { Digital Transformation } \\
\text { Platform }\end{array}$ & Cronbach's alpha $=0,853$ \\
\hline Infrastructure platform & NTCDS1 & 6.43 & 10.535 & .644 & .837 \\
\hline Strategy for DT & NTCDS2 & 7.16 & 10.520 & .699 & .811 \\
\hline IT applications for DT & NTCDS3 & 6.63 & 11.070 & .724 & .802 \\
\hline Innovation management & NTCDS4 & 6.81 & 11.050 & .721 & .803 \\
\hline Smart Manufacturing & Cronbach's alpha $=0,874$ & \\
\hline $\begin{array}{l}\text { Using sensor system in- } \\
\text { process monitoring }\end{array}$ & SXTM1 & 5.49 & 9.170 & .693 \\
\hline Building IT solutions & SXTM2 & 5.40 & 8.644 & .779 & .819 \\
\hline $\begin{array}{l}\text { Building a cloud-based } \\
\text { database }\end{array}$ & SXTM3 & 5.54 & 8.891 & .763 & .827 \\
\hline $\begin{array}{l}\text { Application of Industry } 4.0 \\
\text { solutions }\end{array}$ & SXTM4 & 5.55 & 8.479 & .694 & .856 \\
\hline
\end{tabular}

\section{Factors the Readiness of SMEs DT}

The exploratory factor analysis process is carried out through 4 testing steps as follows:

1) Factor loading of all observed variables is $>$ 0.5 , proving that these observed variables have high reliability and are considered to be of practical significance (Menke, 2018);

2) Kaiser-Meyer-Olkin criterion (KMO) $=0.96$ $>0.5$ satisfy the suitability of factor analysis if $0.5 \leq \mathrm{KMO} \leq 1$ (Menke, 2018);
3) Sig. $=0.00<0.05$ in Bartlett's test indicates that there are statistically significant correlations between observed variables, so the observations are suitable for factor analysis;

4) Cumulative variance $=67.340 \%$, meaning $67.340 \%$ of the total variance is explained by the factors, and this cumulative variance greater than $50 \%$ is suitable for factor analysis (Menke, 2018). 
After performing the tests, the next step is to perform factor rotations to ensure that the observed variables belong to the factors, have factor loading coefficients greater than 0.5 , and are evenly distributed over the factors. According to the Kaiser criterion, two factors were determined that characterize the readiness of Vietnamese SMEs DT. Variable NTCDS1 "Infrastructure platform" has factor loadings with selected factors 0.565 and 0.553 , which indicates the impossibility of including this variable in any one factor (Menke, 2018).

The results of the factor rotation in Table 4 show that there is a disturbance between the variables of the factor groups, formed according to the results of the analysis of the relevant literature (Table 2) and according to the results of factor analysis (Table 4). So it is necessary to rename the factors accordingly as follows, based on the results of factor analysis:

Factor $\mathrm{F} 1$ is formed based on observed variables (SXTM3, SXTM4, SXTM2, NTCDS4, NTCDS2, NTCDS3, SXTM1, QLNS4) belonging to the group of factors "Smart production" and "Digital transformation platform" and element "Measurement of performance" should be named "Smart production and digital operation system."

Factor F2 is formed based on observed variables (QLDN1, QLDN3, QLDN2, QLNS1, QLNS2, QLNS3, QLDN4) belonging to the component "Business management" and "Productivity management" so-named "Business and process management."

Table 4: Factor rotation matrix in factor analysis results

\begin{tabular}{|l|l|l|l|}
\hline \multicolumn{1}{|c|}{ Labels of observed variable } & \multirow{2}{*}{$\begin{array}{c}\text { Observed } \\
\text { variable }\end{array}$} & \multicolumn{2}{c|}{ Component } \\
\cline { 3 - 4 } & SXTM3 & Factor F1 & Factor F2 \\
\hline Building a cloud-based database & SXTM4 & 0.83 & \\
\hline Application of Industry 4.0 solutions & SXTM2 & 0.75 & \\
\hline Building IT solutions & NTCDS4 & 0.74 & \\
\hline Innovation management & NTCDS2 & 0.72 & \\
\hline Strategy for DT & NTCDS3 & 0.70 & \\
\hline IT applications for DT & SXTM1 & 0.66 & \\
\hline $\begin{array}{l}\text { Using sensor system to monitor the process } \\
\text { (Sensor) }\end{array}$ & & & \\
\hline Performance measurement & QLNS4 & 0.61 & \\
\hline Leadership & QLDN1 & & 0.84 \\
\hline Human Resources & QLDN3 & & 0.81 \\
\hline Customer & QLDN2 & & 0.76 \\
\hline Standards, management tools & QLNS1 & & 0.76 \\
\hline Level of application & QLNS2 & & 0.72 \\
\hline Process control & QLNS3 & & 0.71 \\
\hline Innovation culture & QLDN4 & & 0.69 \\
\hline KMO & & & 0.96 \\
\hline Sig. in Bartlett's test & & & 0.00 \\
\hline
\end{tabular}

The considered indexes to evaluate Model Fit include: Chi squared $/ \mathrm{df}=4.251<5$, satisfy the acceptable level; comparative fit index $(\mathrm{CFI})=$ $0.909>0.9$ satisfy the good level; goodness of fit index $(\mathrm{GFI})=0.950>0.95$ satisfy the very good level; root mean square error of approximation $($ RMSEA $)=0.080 \leq 0.08$ satisfy the good level (Menke, 2018). Thus, there is a basis to conclude that the measurement model fits well with the real data.

\section{The Readiness of Vietnamese SMEs DT}

FDI enterprises, state-owned enterprises are further along with DT than non-state enterprises. The readiness measurement shows that DT is still in the early stages of development in Vietnam (Table 5). 
Table 5: Overall results for DT readiness

\begin{tabular}{|l|l|l|l|l|l|}
\hline \multirow{1}{*}{$\begin{array}{c}\text { Enterprise } \\
\text { groups* }\end{array}$} & $\begin{array}{c}\boldsymbol{R}_{D T} \text { value range, } \\
\text { points }\end{array}$ & \multicolumn{4}{|c|}{ The share of enterprises from the corresponding level } \\
& & & \multicolumn{4}{|c|}{$\begin{array}{c}\text { FDI } \\
\text { of the } \boldsymbol{R}_{D T} \text { indicator }\end{array}$} \\
\cline { 3 - 6 } & & $\begin{array}{c}\text { Non-state } \\
\text { enterprises }\end{array}$ & $\begin{array}{c}\text { State-owned } \\
\text { enterprises }\end{array}$ & Total \\
\hline Newcomers & {$[1.0 ; 2.0]$} & $36.85 \%$ & $77.03 \%$ & $48.39 \%$ & $72.07 \%$ \\
\hline Learners & $(2.0 ; 3.4]$ & $31.58 \%$ & $16.24 \%$ & $24.19 \%$ & $17.77 \%$ \\
\hline Leaders & $(3.4 ; 5.0]$ & $31.58 \%$ & $6.73 \%$ & $27.41 \%$ & $10.15 \%$ \\
\hline Average readiness & & 2.84 & 1.91 & 2.71 & 2.04 \\
\hline
\end{tabular}

* - DT enterprise groups

$72.07 \%$ of enterprises still have only a low level of DT and belong to the "Newcomers" group in the use of digital technologies. To date, $17.77 \%$ of enterprises are classified as "Learners." $10.15 \%$ of enterprises have so far reached the level of "Leaders." Since this level is the target vision of DT, it is not surprising that very few enterprises have reached this level. Reaching this target vision is a long-term goal for most companies in the sector. However, among the three groups of enterprises, non-state enterprises have the lowest level of readiness for DT. A 77.03\% of non-state enterprises are classified as "Newcomers" and are so far involved in DT to a minimal degree. The FDI enterprises and Stateowned enterprises are much more advanced in DT than non-state enterprises as a whole. The current DT readiness of Vietnam's enterprises, on a scale of 1 to 5 , is 2.04 . The score for the non-state enterprises as a whole is lowest at 1.907.

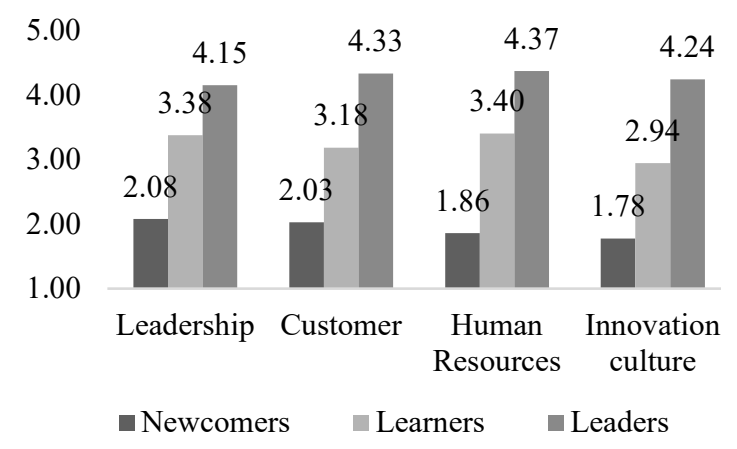

Figure 1a: The dimension of enterprise management

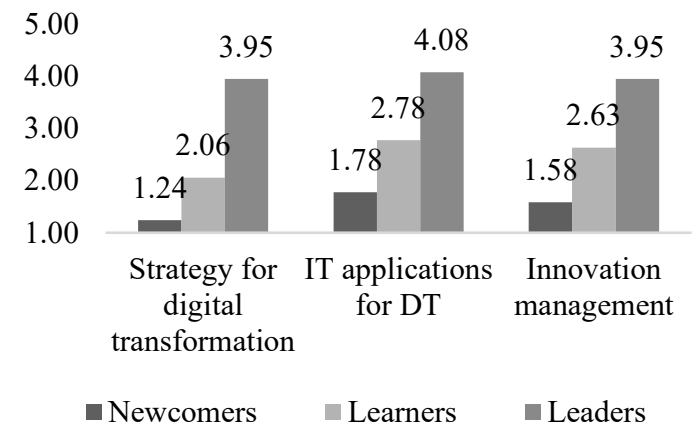

Figure 1c: The dimension of the DT platform

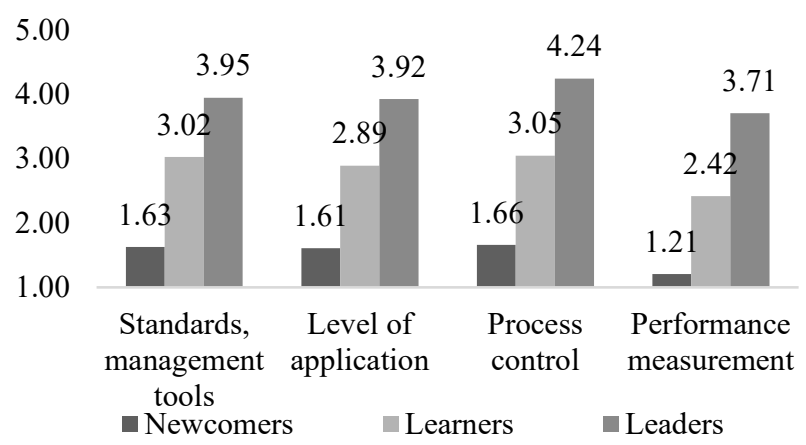

Figure 1b: The dimension of productivity management

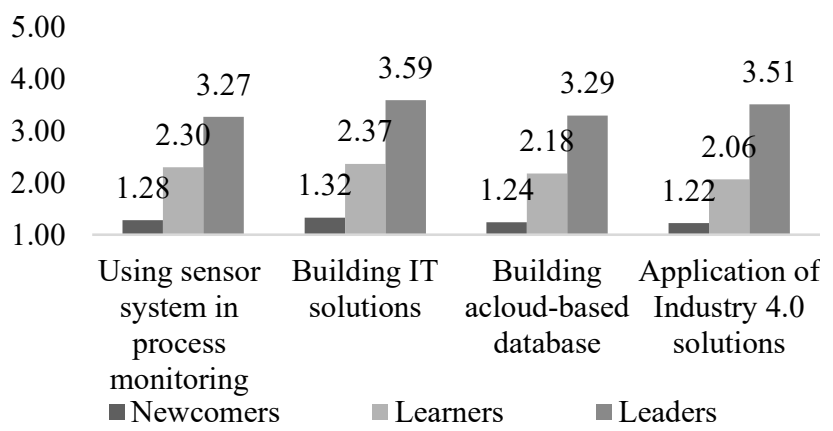

Figure 1d: The dimension of smart manufacturing

Figure 1: The readiness of Vietnamese SMEs DT indicators values

Source: Authors' work

The dimension of Enterprise Management groups: 1.93 points for newcomers, 3.36 points has the highest scores in all three enterprises for learners, and 4.41 points for leaders (Fig. 
1a). This is a dimension that enterprises put on top and focus on development. In this model, this dimension is evaluated by four criteria: Leadership, Customers, Human resources, Innovation culture. Enterprises leaders moving towards DT need to identify the management principles needed for businesses, be courageous, and look toward the future. Naturally, Leaders will also be responsible for developing the vision, mission, policy, and goals in their statement. The criteria of Innovation culture is also a point needed to improve, especially the group of business learners, currently only 2.94 points.

The dimension of Productivity Management is stable when measured. In this model, this dimension is evaluated by four criteria: Standards, management tools; Level of application; Process control; Performance measurement (Fig. 1b). However, the criteria of Performance measurement are in need of improvement. Currently, this index is only 1.21 points for newcomers, 2.42 points for learners, and 3.71 points for leaders. The dimension of the DT Platform is evaluated by three criteria: Strategy for DT; IT applications for DT; Innovation management (Fig. 1c). However, the criteria of Strategy for DT has a very low score in the group of newcomers and learners, just 1.24 and 2.06, respectively. This is much lower when compared to overall scores.

The dimension of Smart Manufacturing has the lowest scores in all three enterprises groups: 1.26 points for newcomers, 2.27 points for learners and 3.53 points for leaders (Fig. 1d).

\section{The Efficiency of Vietnamese SMEs DT to Ensure Their Sustainable Development}

Using the Kaiser criterion, it was determined that the sustainable development of Vietnamese SMEs is described by two factors with values not lower than 1.0. This is a factor of economic and environmental efficiency (FEF), formed by indicators of return on assets and equity capital, cost coverage, growth rates of labor productivity, the share of payments associated with the emission of pollutants into the atmosphere in the company's income; and the factor of the development of labor potential (FLAB). This combined the indicators of the growth rates of the average wage per employee and the wage fund of the enterprise, the rate of retirement of personnel (Table 6 ). Factor loads between the indicated indicators and the corresponding factors are not less than 0.6; the value of the cumulative percentage of variance is $88.3 \%$, which indicates the completeness of factorization (Menke, 2018).

Table 6: Load factors between sustainability indicators and factors of Vietnamese SMEs

\begin{tabular}{|l|l|l|l|}
\hline \multicolumn{1}{|c|}{ Sustainable development indicators } & \multicolumn{2}{l}{$\begin{array}{l}\text { Observed } \\
\text { variable }\end{array}$} & \multicolumn{1}{c|}{ Component } \\
\cline { 2 - 4 } & $R O A$ & 0.80 & $F_{L A B}$ \\
\hline Return on assets & $C R$ & 0.78 & \\
\hline Cost coverage & $R O E$ & 0.75 & \\
\hline Return on equity & $L P$ & 0.71 & \\
\hline Labor productivity growth rates compared to 2019 & -0.60 & \\
\hline $\begin{array}{l}\text { The share of payments of the enterprise associated with the } \\
\text { emission of pollutants into the atmosphere in the income of } \\
\text { the enterprise }\end{array}$ & $E M$ & & \\
\hline $\begin{array}{l}\text { The growth rate of the average wage per employee compared } \\
\text { to 2019 }\end{array}$ & $S A L$ & & 0.91 \\
\hline $\begin{array}{l}\text { Retirement rate } \\
\text { The growth rate of the wage fund of the enterprise compared } \\
\text { to 2019 }\end{array}$ & RR & & - \\
\hline Factor dispersion,\% Cumulative percentage of variance,\% & & & 0.85 \\
\hline Factor dispersion,\% Cumulative percentage of variance,\% & & 46.3 & 42.0 \\
\hline
\end{tabular}

The first factor characterizes the sustainability of SMEs development from the standpoint of operational efficiency. The second factor characterizes the movement of personnel (retirement rate) and includes indicators (growth rates of average wages and wages fund), which characterize the presence of financial motives to ensure the efficiency of 
personnel and sustainable development of the enterprise. The selected factors were used as sub-indicators in the integrated model for assessing the sustainable development of
Vietnamese SMEs (pair correlation coefficient is 0.18 ). The sustainable development levels of Vietnamese SMEs are summarized in Table 7.

Table 7: Ranges of levels of private and integral indicators of sustainable development of Vietnamese SMEs

\begin{tabular}{|c|c|c|c|c|c|c|c|}
\hline \multirow{2}{*}{ Indicator } & \multicolumn{3}{|c|}{ Levels } & \multirow{2}{*}{ Indicator } & \multicolumn{3}{|c|}{ Levels } \\
\hline & Low & Medium & High & & Low & Medium & High \\
\hline$R O A$ & $\begin{array}{l}(-\infty ;- \\
0.02]\end{array}$ & {$[0 ; 0.08]$} & $\begin{array}{l}{[0.18} \\
+\infty)\end{array}$ & $W A G$ & {$[0 ; 0.83]$} & {$[0.95 ; 1.05]$} & $\begin{array}{l}{[1.12 ;} \\
+\infty)\end{array}$ \\
\hline$R O E$ & $(-\infty ; 0]$ & {$[0 ; 0.12]$} & $\begin{array}{l}{[0.23} \\
+\infty)\end{array}$ & $R R$ & {$[0 ; 0.16]$} & {$[0.24 ; 0.49]$} & $\begin{array}{l}{[0.63 ;} \\
1]\end{array}$ \\
\hline$L P$ & {$[0 ; 0.92]$} & {$[1.01 ; 1.09]$} & $\begin{array}{l}{[1.20} \\
+\infty)\end{array}$ & $E M$ & [0;0.19] & {$[0.24 ; 0.36]$} & $\begin{array}{l}{[0.48 ;} \\
1]\end{array}$ \\
\hline$C R$ & {$[0 ; 0.19]$} & {$[0.29 ; 0.38]$} & $\begin{array}{l}{[0.44} \\
+\infty)\end{array}$ & $F_{E F}, F_{L A B}, I_{S D}$ & {$[0.1 ; 0.26]$} & {$[0.42 ; 0.58]$} & \begin{tabular}{|l}
{$[0.74 ;$} \\
$0.9]$ \\
\end{tabular} \\
\hline$S A L$ & {$[0 ; 0.87]$} & {$[0.92 ; 1.08]$} & $\begin{array}{l}{[1.19} \\
+\infty)\end{array}$ & & & & \\
\hline
\end{tabular}

$R O A$ is the return on assets; $R O E$ is the return on equity; $L P$ is the growth rates of labor productivity compared to 2019; $C R$ is the cost coverage ratio; $S A L$ is the growth rate of the average wage per employee compared to 2019; $W A G$ is the growth rate of the company's wage fund compared to 2019; $R R$ is the staff retirement rate; $E M$ is the share of payments of the company associated with the emission of pollutants into the atmosphere in the company's income; $F_{E F}$ is the factor of economic and ecological efficiency; $F_{L A B}$ is the factor in the development of labor potential; $I_{S D}$ is the integral indicator of sustainable business development.

Private indicators of sustainable development are mainly stimulators of development, and high levels indicate sustainable business development. It serves as the indicator of the share of payments of the enterprise associated with the emission of pollutants into the atmosphere in the enterprise's income. Also, the rate of retirement of personnel is disincentives. The high level of these indicators indicates a low level of sustainable development due to ineffective use of labor potential and ineffective environmental management at the enterprise.

The grading of Vietnamese SMEs by the level of sustainable development is shown in Table 8.

Table 8: Distribution of Vietnamese SMEs by sustainability level

\begin{tabular}{|l|l|l|l|l|}
\hline \multirow{2}{*}{$\begin{array}{c}\text { Sustainable } \\
\text { development } \\
\text { level }\end{array}$} & \multicolumn{4}{c|}{ The share of enterprises from the corresponding level of the $I_{S D}$} \\
& \multicolumn{1}{|c|}{$\begin{array}{c}\text { FDI } \\
\text { indicator }\end{array}$} & \multicolumn{1}{c|}{$\begin{array}{c}\text { Non-state } \\
\text { enterprises }\end{array}$} & $\begin{array}{c}\text { State-owned } \\
\text { enterprises }\end{array}$ & Total \\
\cline { 2 - 5 } & $30.56 \%$ & $52.98 \%$ & $34.21 \%$ & $50.00 \%$ \\
\hline Low & $2.78 \%$ & $2.98 \%$ & $5.26 \%$ & $3.14 \%$ \\
\hline Intermediate & $36.11 \%$ & $33.49 \%$ & $31.58 \%$ & $33.53 \%$ \\
\hline Medium & $2.78 \%$ & $2.75 \%$ & $2.63 \%$ & $2.75 \%$ \\
\hline Intermediate & $27.78 \%$ & $7.80 \%$ & $26.32 \%$ & $10.59 \%$ \\
\hline High & 0.48 & 0.35 & 0.47 & 0.36 \\
\hline Mean value & & &
\end{tabular}

The construction of linear regression models did not confirm a direct relationship between the readiness of Vietnamese SMEs DT $\left(R_{D T}\right)$ and the integral indicator of sustainable development of enterprises $\left(I_{S D}\right)$. In this regard, nonlinear estimation was used (Table 9 ). 
Table 9: Models for assessing the impact of the readiness of Vietnamese SMEs DT readiness on the sustainability of their development

\begin{tabular}{|c|c|c|c|}
\hline Enterprises* & Model & t-statistic ${ }^{* *}$ & Graphic interpretation \\
\hline Newcomers & $I_{S D}=0.46 / R_{D T}+0.13$ & $t\left(R_{D T}\right)=7.24$ & 1 Newcomers \\
\hline Learners & $\begin{array}{l}I_{S D}=0.69 \times R_{D T}^{2} \\
+3.99 \times R_{D T}-4.98\end{array}$ & $\begin{array}{l}t\left(R_{D T}^{2}\right)=-2.94 \\
t\left(R_{D T}\right)=5.62\end{array}$ & 0.6 \\
\hline Leaders & $\begin{array}{l}I_{S D}=-0.17 \times R_{D T}^{2} \\
+1.65 \times R_{D T}-3.13\end{array}$ & $\begin{array}{l}t\left(R_{D T}^{2}\right)=-2.98 \\
t\left(R_{D T}\right)=4.15\end{array}$ & 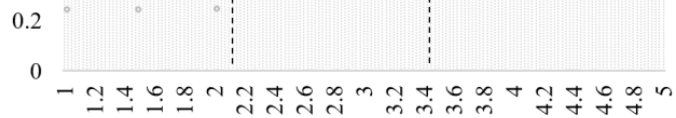 \\
\hline
\end{tabular}

* - DT enterprise groups;

** - t-criterion level.

The adequacy of the models was confirmed by the size and variability of the sample of the surveyed SME business units in Vietnam. It represented 368 enterprises from the "Newcomers" group, 91 enterprises from the "Learners" group, and 52 enterprises from the "Leaders" group. The number of observations exceeds the number of variables by at least 26 times, which indicates the sufficiency of the sample (Jenkins \& Quintana-Ascencio, 2020). The empirical values of the t-criterion exceed the critical ones at a significance level of $p=$ 0.05 and are in the $|2.94|-|7.24|$ range.

\section{DISCUSSION AND CONCLUSION}

As part of the study, an empirical model was developed, which made it possible to conclude that the studied Vietnamese SMEs are predominantly at a low level of sustainable development (50\%). Non-state enterprises mostly represent this group of enterprises, $52.98 \%$ of which have a low level of sustainable development. $33.53 \%$ of enterprises are at the average level, $10.59 \%$ are at the high level. Intermediate levels are represented by $3.14 \%$ of enterprises for the transitional level between low and medium, $2.75 \%$ of enterprises for the level intermediate between medium and high. The results indicate the need to improve economic and environmental efficiency and develop labor potential to ensure sustainable business development. In contrast to the existing ones, the developed model considers the peculiarities of the functioning and the current level of development of SMEs in a particular country (Hitz \& Schwer, 2018; Castelo-Branco et al., 2019; Schwer \& Hitz, 2018). It can serve as a tool for ongoing diagnostics for effective adaptation to DT at any stage of enterprise development. It allows one to assess the differentiated nature of the impact of the level of use of digital technologies on the sustainability of SME development (Shahrom et al., 2021).

The analysis results showed the differentiated nature of the influence of the DT readiness indicator on the sustainability of business development. For enterprises at the stage of episodic implementation of digital technologies, the expansion of the scale of their use leads to a decrease in sustainable development. The revealed pattern is explained by the fact that for these enterprises, the positive effect of digital technologies is leveled out due to the significant costs associated with the introduction of technologies, the rejection of new technologies by workers, and psychological tension negatively affects labor productivity. Further implementation of digital technologies (for the "Learners" group of enterprises) allows you to experience such positive results as increased labor productivity, capital productivity, environmental friendliness of the production process, which leads to sustainable business development. This positive impact on the sustainability of development is observed until a certain point, after which the decline in the integral indicator of sustainable development begins. The turning point comes as a result of the fact that the use of digital technologies makes it necessary to optimize the workforce of enterprises because some of the work previously performed by personnel becomes automated and requires less labor force participation. There is a reduction in staff and a decline in 
sustainable development in terms of its social component in such conditions.

For "Leaders" enterprises, the development of digital technologies has a positive effect on the dynamics of the integral indicator of sustainable development. The use of digital technologies makes it possible to increase economic efficiency by increasing labor productivity, reducing the cost of manufacturing products or providing services, reducing the percentage of rejects resulting from using newer and improved technologies, and increasing the validity of management decisions. In the environmental component, a positive impact on the sustainability of development is reflected by reducing environmental pollution and associated costs. Social development is ensured because, despite the reduction in the number of personnel, the demand for highly qualified workers with a higher level of remuneration is growing at enterprises. The revealed patterns indicate that the introduction of digital technologies in the long term ensures sustainable business development.

The results obtained are based on a sample of Vietnamese enterprises, which does not allow their implementation in the practice of SMEs in other countries. In addition, within the framework of this study, a forecast of sustainable development of the SME sector was not carried out depending on the level of DT and the potential level of effect for the country's economy. These issues require extensive research and will be studied by us in our prospective studies.

\section{REFERENCES}

Axmann, B., \& Harmoko, H. (2020). Industry 4.0 readiness assessment: comparison of tools and introduction of new tool for SME. Technical Journal, 14, 212-217. https://doi.org/10.31803/tg20200523195016

Berman, S., \& Papas, P. (2021). Creating new business models where digital meets physical. https://www.ibm.com/thoughtleadership/institute-businessvalue/report/digital-transformation

Brunet-Thornton, R., Cramer, T., \& Jirsák, P. (2019). A research agenda on Czech attitudinal perspectives in an era of digital transformation. Journal of Eastern European and Central Asian

Research, 61), 99-112. https://doi.org/10.15549/jeecar.v6i1.277

Cameron, A., Pham, T.H., Atherton, J., Nguyen, D.H., Nguyen, T.P., Tran, S.T., Nguyen, T.N., Trinh, H.Y., \& Hajkowicz, S. (2019). Vietnam's future digital economy - towards 2030 and 2045. Brisbane:

CSIRO.

https://doi.org/10.25919/5d642c3eaf5aa

Castelo-Branco, I., Cruz-Jesus, F., \& Oliveira, T. (2019). Assessing Industry 4.0 readiness in manufacturing: Evidence for the European Union. Computers in Industry, 107, 22-32. https://doi.org/10.1016/j.compind.2019. 01.007

Chen, J., Huang, J., Su, W., Štreimikienė, D., \& Baležentis, T. (2021). The challenges of COVID-19 control policies for sustainable development of business: Evidence from service industries. Technology in Society, 66, 101643.

https://doi.org/10.1016/j.techsoc.2021.1 01643

Galiakhmetova, M.R., Koretskiy, V.P., Mardanova, I.M., \& Józsa, L. (2019). Methods and approaches of complexity theory and fuzzy logic for intensity of university research in terms of creative work to be estimated. Journal of Eastern European and Central Asian Research, G(1), 86-98. https://doi.org/10.15549/jeecar.v6i1.241

Google Forms. (2021). Assessing the digital transformation readiness. https://docs.google.com/forms/d/e/1FAIp QLSCMEQMK_9ojP6CWPCIgN8QLWTaQg kGZbLiiHmh63XAVaJgIDg/viewform

Hitz, C., \& Schwer, K. (2018). The role of IT governance in digital operating models. Journal of Eastern European and Central Asian Research, 5(2), 61-79. https://doi.org/10.15549/jeecar.v5i2.210

Jenkins, D.G., \& Quintana-Ascencio, P.F. (2020). A solution to minimum sample size for regressions. PLoS One, 15 , e0229345.

https://doi.org/10.1371/journal.pone.022 9345

Jung, K., Kulvatunyou, B., Choi, S., \& Brundage, M.P. (2016). An overview of a smart manufacturing system readiness 
assessment. In: Nääs, I., Vendrametto, O., Reis, J.M., Gonçalves, R.F., Silva, M.T., von Cieminski, G., \& Kiritsis, D. (eds.) Advances in Production Management Systems. Initiatives for a Sustainable World. APMS 2016. IFIP Advances in Information and Communication Technology, Vol. 488 (pp. 705-712). Cham: Springer. https://doi.org/10.1007/978-3-31951133-7_83

Khan, I.S., Ahmad, M.O., \& Majava, J. (2021). Industry 4.0 and sustainable development: A systematic mapping of triple bottom line, Circular Economy and Sustainable Business Models perspectives. Journal of Cleaner Production, 297, 126655. https://doi.org/10.1016/j.jclepro.2021.12 6655

Khaw, K.W., Khoo, M.B.C., Castagliola, P., \& Rahim, M.A. (2018). New adaptive control charts for monitoring the multivariate coefficient of variation. Computers \& Industrial Engineering, 126, 595-610. https://doi.org/10.1016/j.cie.2018.10.016

Lichtblau, K., Stich, V., Bertenrath, R., Blum, M., Bleider, M., Millack, A., Schmitt, K., Schmitz, E., \& Schröter, M. (2015). Impuls - Industrie 4.0 readiness. Aachen, Cologne. https://industrie40.vdma.org/documents /4214230/26342484/Industrie_40_Readi ness_Study_1529498007918.pdf/0b5fd5 21-9ee2-2de0-f377-93bdd01ed1c8

Massachusetts Institute of Technology. (2021). Fall 2021 issue. MIT Sloan Management Review, 63(1). https://sloanreview.mit.edu/issue/2021fall/

Menke, W. (2018). Factor analysis. In Geophysical data analysis (pp. 207-222). Academic Press. https://doi.org/10.1016/B978-0-12813555-6.00010-1

Ministry of Information and Communications. (2020). Viewpoints and goals of National Digital Transformation Program. https://english.mic.gov.vn/Pages/TinTuc/ 145793/Viewpoints-and-goals-ofNational-Digital-TransformationProgram.html
Ministry of Planning and Investment. (2021). Over 57.5 per cent of Vietnamese SMEs struggle with digital transformation: How can they cope with the challenge? https://vir.com.vn/over-575-per-cent-ofvietnamese-smes-struggle-with-digitaltransformation-how-can-they-copewith-the-challenge-83754.html

Mittal, S., Kahn, A., Romero, D., \& Wuest, T. (2018). A critical review of smart manufacturing \& Industry 4.0 maturity models: Implications for small and medium-sized enterprises (SMEs). Journal of Manufacturing Systems, 49, 194-214. https://doi.org/10.1016/j.jmsy.2018.10.0 05

Nick, G., Szaller, Á., Bergmann, J., \& Várgedő, T. (2019). Industry 4.0 readiness in Hungary: model, and the first results in connection to data application. IFACPapersOnLine, 52(13), 289-294. https://doi.org/10.1016/j.ifacol.2019.11.1 85

PwC. (2021). Vietnam digital readiness report.

https://www.pwc.com/vn/en/publication s/2021/pwc-vietnam-digital-readinessreport-en.pdf

Quynh, NX (2021). Vietnam wants digital economy equal to $20 \%$ of GDP in four years.

https://www.bloomberg.com/news/artic les/2021-08-12/vietnam-wants-digitaleconomy-equal-to-20-of-gdp-in-fouryears

Rosenberg L. (2020). Meet business challenges head-on with a new approach to network operations. https://www.cisco.com/c/dam/m/en_in/ pdf/meet-business-challenges-headon.pdf

Schuh, G., Anderl, R., Dumitrescu, R., Krüger, A., \& ten Hompel, M. (2020). Industrie 4.0 maturity index. Managing the digital transformation of companies - update 2020. Munich: National Academy of Science and Engineering. https://en.acatech.de/publication/industr ie-4-0-maturity-index-update-2020/

Schwer, K., \& Hitz, C. (2018). Designing organizational structure in the age of digitization. Journal of Eastern European 
and Central Asian Research, 5(1), 11. https://doi.org/10.15549/jeecar.v5i1.213

Shahrom, M., Seman, S.A.A., \& Demong, N.A.R. (2021). The acceptance of digital workforce environments among millennials. Hong Kong Journal of Social Sciences, 57, 196-204.

http://hkjoss.com/index.php/journal/arti cle/view/434

Singapore Economic Development Board. (2019). The smart industry readiness index.

https://www.edb.gov.sg/en/aboutedb/media-releases-

publications/advanced-manufacturingrelease.html

Taherdoost, H. (2017). Determining sample size; how to calculate survey sample size. International Journal of Economics and Management Systems, 2, 237-239. https://www.researchgate.net/publicatio n/322887480_Determining_Sample_Size _How_to_Calculate_Survey_Sample_Size

World Economic Forum. (2021). Reports. https://www.weforum.org/reports

\section{Appendix 1: Questionnaire}

\section{Dear respondents,}

Indicate to what extent you can agree with the statements of the questionnaire regarding the DT readiness of the enterprise where you work:

1. Leadership: The leadership of your enterprise is aware of the need to digitalize business and supports digital transformation initiatives. The management defines the management principles aimed at business digitalization.

2. Customer: The use of digital technologies allows you to optimize relationships with customers and increase their satisfaction.

3. Human Resources: The reason for the improvement in the quality and satisfaction of work is the use of digital technologies.

4. Innovation culture: Your enterprise has a developed innovative culture. Innovation is well received by management and employees.
5. Standards, management tools: Your enterprise has developed standards that govern the digital transformation process.

6. Level of application: Your enterprise pursues the course on digitalization and innovation.

7. Process control: The process of introducing digital technologies is regulated, the stages and tasks of digitalization are determined, the digitalization process is monitored.

8. Performance measurement: The use of digital technologies has boosted labor productivity in your enterprise, while there is potential for further productivity gains.

9. Infrastructure platform: Your enterprise has a well-developed infrastructure for effective digitalization.

10. Strategy for DT: Your enterprise has its strategy for DT.

11. IT applications for DT: The enterprise operates IT applications for DT, expanding their functionality.

12. Innovation management: The activities of your enterprise are aimed at the introduction of new products and services, production and management processes.

13. Using sensor system in-process monitoring: Your enterprise is using sensor system in-process monitoring.

14. Building IT solutions: Your enterprise uses and creates new IT solutions to improve business efficiency.

15. Building a cloud-based database: Your enterprise uses a cloud-based database.

16. Application of Industry 4.0 solutions: Your enterprise uses Industry 4.0 solutions. 


\section{ABOUT THE AUTHORS}

Nguyen Thi Xuan Hoa, email: hoan65110@gmail.com

Nguyen Thi Xuan Hoa is a lecturer and researcher in Industrial Management, School of Economics and Management, Ha Noi University of Science and Technology, Viet Nam. Her teaching and research interests include Lean manufacturing, Smart Manufacturing, Digital Transformation, Industry 4.0, Total productivity improvement, Supply contract, Supply chain design, Inventory policies, and Warehouse management. She has published articles in peerreviewed international journals, international conference proceedings.

Nguyen Thanh Tuyen is a Master of Science student in Industrial Management, School of Economics and Management, Hanoi University of Science and Technology, Vietnam. His research interests include digital transformation, planning and production management, intralogistics, and inventory control. 